\title{
FRP-to-Softwood Joints: Experimental Investigation
}

\author{
J. Wan \& S.T. Smith (stsmith@hku.hk) \\ Department of Civil Engineering, The University of Hong Kong, China \\ P.Z. Qiao \\ Department of Civil and Environmental Engineering, Washington State University, USA
}

\begin{abstract}
A proper understanding of the interfacial behaviour between timber and bonded fibre-reinforced polymer (FRP) composites will assist in the rational and optimal design of FRP strengthening works for timber structures. To enhance this understanding, a series of single-lap FRP-to-timber joint shear tests are reported herein in which the strength of the bond between the FRP and timber is examined. The shear tests are conducted on softwood (Pine) which has been strengthened with carbon FRP with the main test variables being the FRP bond length and the growth characteristics of the timber. Extensive strain gauging of the FRP has enabled the onset and propagation of debonding cracks to be monitored. An effective bond length is identified, however, the results also show that timber is a variable material which requires continued investigation.
\end{abstract}

\section{INTRODUCTION}

Timber has been used as a construction material in civil infrastructure (Breyer et al. 2007) throughout the world for several millennia and it is still a popular construction material to this day. Degradation of timber due to mechanical and environmental loadings, as well as the need for the timber to withstand higher loads, can require the timber to be strengthened or repaired. The external bonding of fibre-reinforced polymer (FRP) composites offers a viable solution. A lack of understanding of the bond strength and behaviour of FRP to the timber substrate is, however, hindering the safe and rational design of FRP strengthening.

Tests on the bond strength and behaviour of FRPto-timber are limited. The majority of testing has involved the use of the called modified block-shear test of ASTM D905-03 (2003) (e.g. Davalos et al. 2000, Crews and Smith 2006). This test gives the shear strength of the bond as an average bond stress over the bonded length, however, the surface of the FRP is sandwiched between two pieces of timber. Such positioning does not make it possible to easily monitor the surface of the FRP. Claisse et al.'s (2007) study appears to be one of the few on double-lap FRP-to-timber joint shear specimens in which the surface of the FRP is exposed.

This paper reports the results of a series of tests on single-lap FRP-to-timber joints. These tests form part of a much larger test program at The University of Hong Kong concerned with the strengthening of timber with FRP. For the tests reported herein, Pine (softwood) and carbon FRP (wet lay-up) sheets are the materials of choice, with the two primary test variables being (i) length of bonded FRP, and (ii) timber growth characteristics. All test specimens are instrumented with an extensive arrive of electric resistance strain gauges which help shed light on the interfacial behaviour of the joints. A much more detailed account of the tests reported herein can be found in Wan et al. (2010).

\section{EXPERIMENTAL DETAILS}

The test set-up is shown in Figure 1 and a schematic of a typical joint is shown in Figure 2.

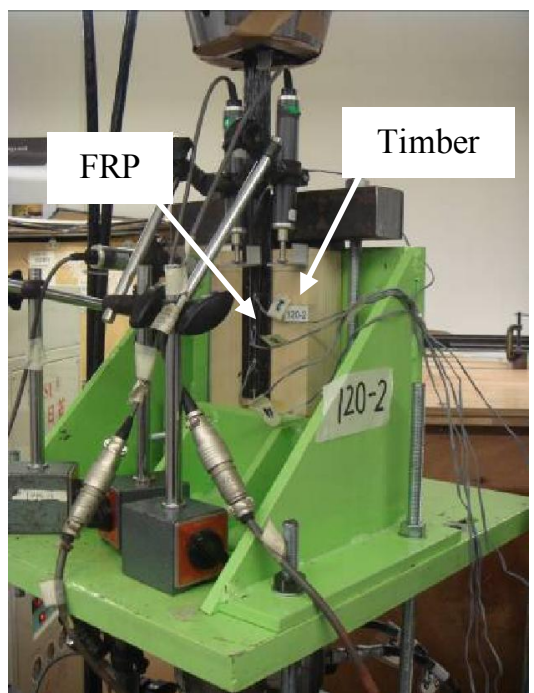

Figure 1. Test set-up. 


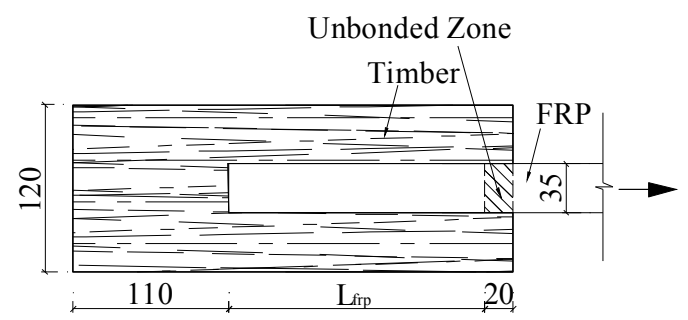

Figure 2. Joint schematic (timber thickness $=50 \mathrm{~mm}$ ).

In total, 52 joint tests were conducted (Wan et al. 2010). Seven different lengths of FRP were investigated with at least seven identical specimens prepared and tested for each length. The lengths $L_{f r p}$ were $15 \mathrm{~mm}, 30 \mathrm{~mm}, 60 \mathrm{~mm}, 90 \mathrm{~mm}, 120 \mathrm{~mm}, 150$ $\mathrm{mm}$ and $180 \mathrm{~mm}$. Pine (softwood) was used and every attempt was made to select test pieces which were relatively free of growth defects such as knots. In some instances small growth defects were, however, present and the effect of such defects is discussed in Section 3. The moisture content of the timber, up to a depth of $8 \mathrm{~mm}$, was measured with a hand-held digital wood moisture tester prior to application of the FRP and was found to be on average $9.5 \%$. All FRP plates were formed in a wet lay-up procedure from two layers of carbon fibre sheet of nominal thickness $0.166 \mathrm{~mm}$ (per sheet).

The surface of the timber was prepared in the following manner prior to bonding of the FRP: (i) sanding of the timber with 120 grit sandpaper, and (ii) cleaning of the prepared surface by spraying with compressed air and then wiping with acetone. Sanding consisted of sweeping the sandpaper back and forward 15 times along the longitudinal axis of the timber (i.e. direction of grain) and also at 45 degrees to the direction of grain. The FRP was then applied to either the A side or B side of the timber as shown in Figure 3. Side A was the side located closest to the pith of the timber. In this case, the annual growth rings were inclined to the edge of the timber and the FRP face. The Side B annual growth rings were oriented predominantly parallel to the edge of the timber. At least three test specimens were prepared and tested for both A and B side bonded FRP.

The properties of two-layered flat FRP coupon tests of $35 \mathrm{~mm}$ width (i.e. the same width and number of fibre sheet layers as the plates used to strengthen the timber joints) were $231 \mathrm{GPa}$ (modulus of elasticity), $2768 \mathrm{MPa}$ (tensile strength) and $1.2 \%$ (rupture strain). Preliminary testing of the compressive and tensile properties of the timber produced relatively consistent elastic moduli on average of about $13.5 \mathrm{GPa}$.

The two longitudinal linear variable differential transformers (LVDT 1 and 2), shown in Figure 4, enabled relative slip between the loaded end of the bonded FRP and adjacent timber to be measured. LVDT 3 confirmed the lateral deflection to be suitably low at an average displacement of about $0.3 \mathrm{~mm}$. Electric resistance strain gauges of $10 \mathrm{~mm}$ gauge length were installed on the surfaces of all FRP plates at $10 \mathrm{~mm}$ from the bond line of the loaded end and then at $30 \mathrm{~mm}$ centres. Load was applied monotonically by displacing the ram of the universal testing machine at a constant rate of $0.3 \mathrm{~mm} / \mathrm{min}$.
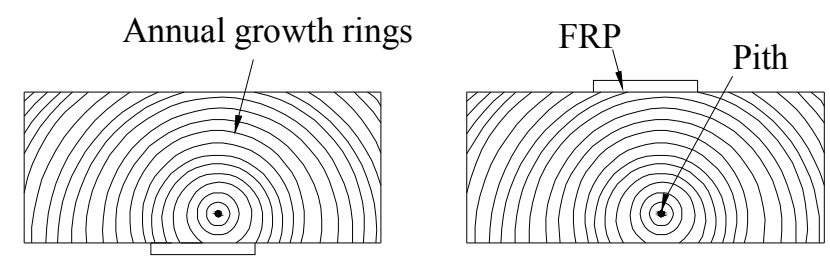

(a) Side A bonded FRP

(b) Side B bonded FRP

Figure 3. Timber growth characteristics and FRP bonding schemes.

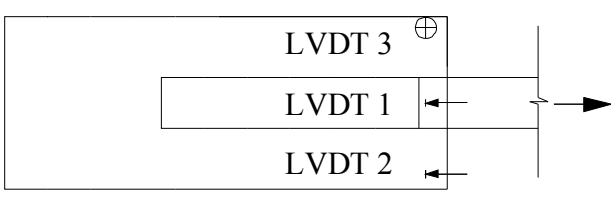

Figure 4. Instrumentation.

\section{EXPERIMENTAL RESULTS}

\subsection{Failure modes}

All specimens failed by debonding at the interface of the FRP and timber substrate and predominantly in the timber. Debonding initiated at the loaded end of the bonded FRP and propagated to the far end. The condition of the debonded surface of the FRP, however, varied. For example, the results for three of the $120 \mathrm{~mm}$ bond length specimens are shown in Figure 5. Figures $5 \mathrm{a}$ and $5 \mathrm{~b}$ show typical failed Side A and Side B specimens, respectively. Side B failures were mainly in the timber, while Side A failures were less often in the timber, for two main reasons: (i) younger wood away from the pith is less dense than older wood closer to the pith, and (ii) the inclination of the annual growth rings. These two factors are, however, intertwined because the growth ring pattern in relation to the cut edge of the timber is a function of the location of the pith. Interlaminar failure between the annual growth rings is particularly evident in Figure $5 b$. Figure 5c shows a Side A specimen which contains a small knot in the bonded area. This specimen (120A-1) recorded the highest failure load for all 120 $\mathrm{mm}$ bond length specimens and this can be attributed to the knot. The knot did not contribute to the highest joint strength in all cases though.

\subsection{Load versus slip}

Figure 6 shows typical load versus slip relationships for specimens with short (30B-1) and long (150B-2) bond lengths in which the slip is based on the LVDT 
measurements. In all cases, the relationship is predominantly linear until debonding occurs. For the shorter bond length specimens, the entire plate debonded quite rapidly once the maximum load was reached. For the longer bond length specimens, a peak load plateau sometimes existed. The peak load plateau began when the FRP started debonding and finished once the FRP had completely debonded. These curves would suggest that once debonding initiates, then there is little to no increase in joint strength. This in turn introduces the concept of an effective bond length in FRP-to-timber joints in which the bond strength will not increase once a certain bonded length of FRP has been reached.

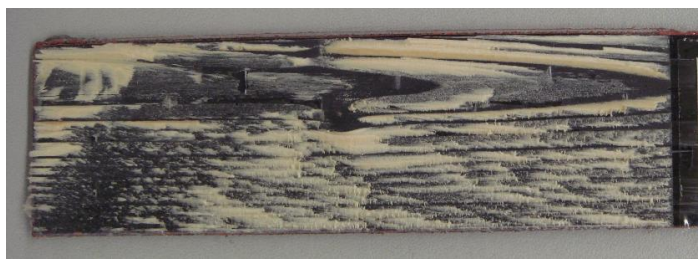

(a) Side A bonded FRP (Specimen 120A-2)

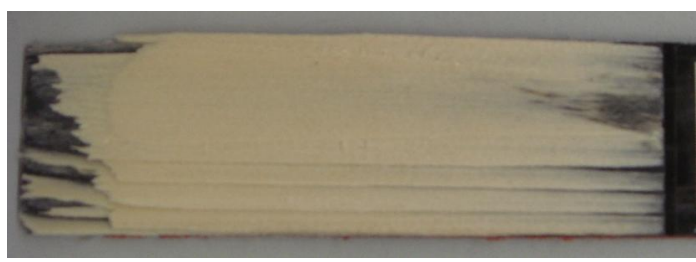

(b) Side B bonded FRP (Specimen 120B-3)

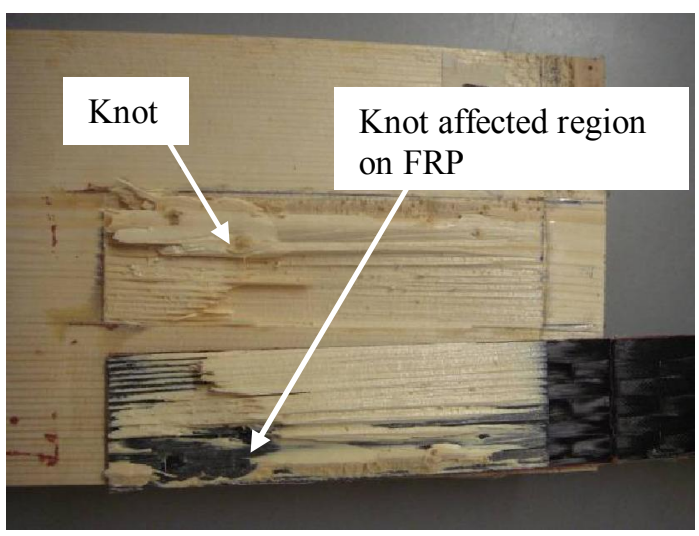

(c) Surface characteristic (Specimen 120A-1)

Figure 5. Debonded FRP surface condition.

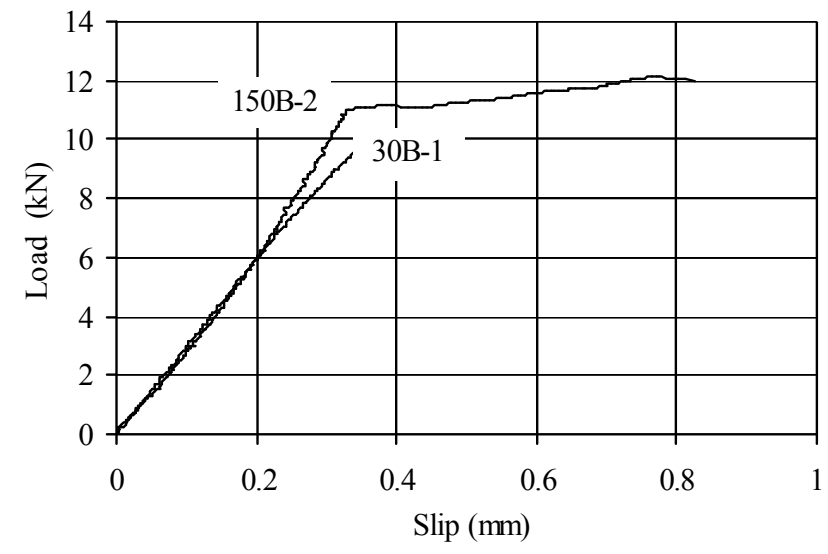

Figure 6. Typical load versus slip responses.

\subsection{Failure load versus bond length}

Figure 7 shows the relationship between failure load and bond length. The data points have been differentiated by Side A or Side B bonded FRP. All joints failed by debonding. The bond strength of the joint for Side B bonded FRP is clearly the lowest for each bond length. The amount of scatter in bond strength of Side A bonded FRP is evident. Such variation can be attributed to the timber characteristics such as location of the pith, inclination of the annual growth rings, and local defects.

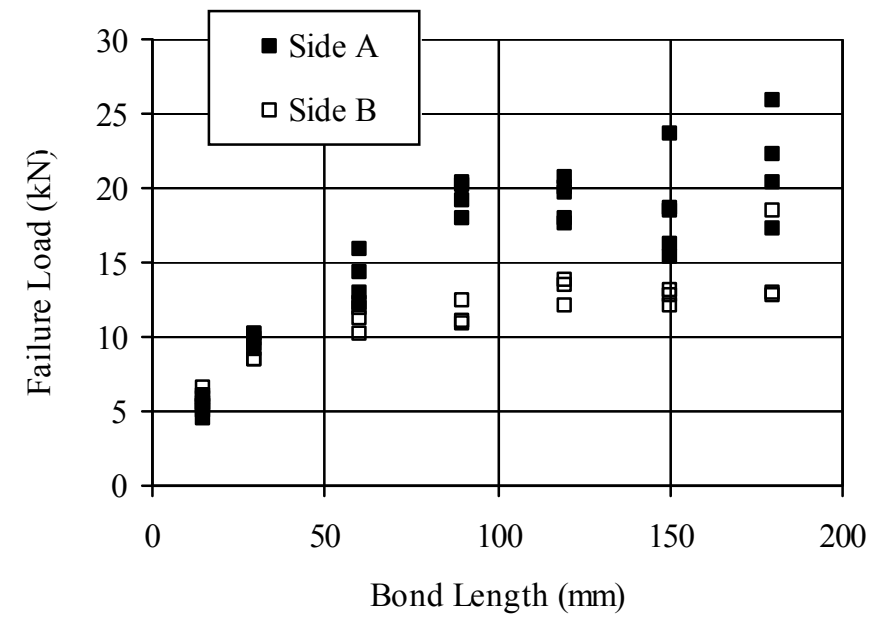

Figure 7. Failure load versus bond length.

\subsection{Load versus strain}

Figure 8 presents typical distributions of strain along the length of bonded FRP. Specimen 150B-2 is selected and this is the same specimen exhibiting the peak load plateau in Figure 6. At the low load ranges of responses in Figure 8, the first $70 \mathrm{~mm}$ or so of FRP plate nearest to the loaded end is providing most of the resistance. Debonding of the FRP initiates at a load and slip of approximately $11.0 \mathrm{kN}$ and $0.33 \mathrm{~mm}$ (based on LVDT readings), respectively. This combination of load and slip represents the approximate start of the sharp change in slope observed in Figure 6. At approximately the same load (11.1 $\mathrm{kN}$ ) but at a larger slip of $0.41 \mathrm{~mm}$, Figure 8 shows the debonding crack to have propagated to the strain gauge located at $10 \mathrm{~mm}$ from the loaded end of the joint. This propagation is evident from the relatively constant strain at the first two strain gauges at $0 \mathrm{~mm}$ and $10 \mathrm{~mm}$ from the loaded end (note that the $0 \mathrm{~mm}$ strain gauge was positioned at $40 \mathrm{~mm}$ from the bonded end of the FRP towards the grips of the universal testing machine). The strain distribution for the last recorded load and slip just prior to complete debonding of the plate is also shown in Figure 8. The extensive debonding of the plate is evident from the large and reasonably constant strains. 


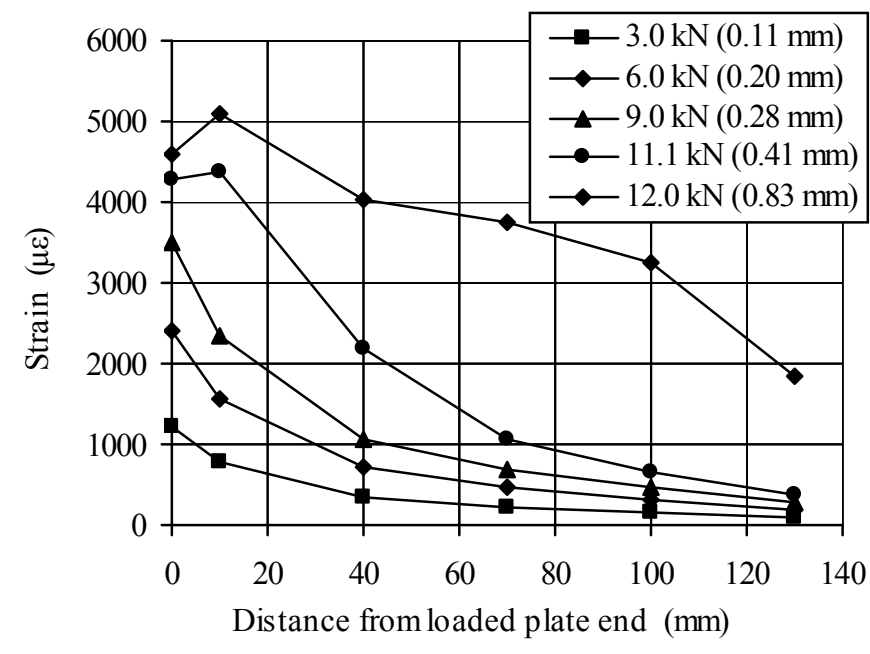

Figure 8. Load versus strain for specimen 150B-2

\section{DISCUSSION}

\subsection{Effective bond length}

Figure 7 reveals the effective bond length for the Side B results to be about $90 \mathrm{~mm}$. The effective bond length for the Side A specimens is not as obvious due to the large scatter of results. For design it is recommended to use the lower bound Side B results until more testing has been undertaken. While the bond strength has the potential to be much larger (i.e. depending on the cut of the timber), it is much less predictable.

\subsection{Inclination of annual growth rings}

For all of the Side B bonded FRP specimens, the FRP was predominantly tangential (i.e. parallel) to the annual growth rings. For all the Side A specimens, the growth rings were predominantly oriented perpendicular to the FRP. The strength of the timber at the FRP-to-timber interface proved the weakest for Side B specimens. This weakness was also demonstrated by the debonded surface of the FRP in which a large portion was covered in thick timber of up to $5 \mathrm{~mm}$ thickness (Figure 5b). The amount of timber remaining attached to the debonded surface of the Side A bonded FRP was on occasions considerably less (i.e. Figure 5a).

\subsection{Location of pith}

The effect of the pith is only evident in the Side A bonded FRP results. The following observations can, however, be made. The radius of curvature of the growth rings in the immediate vicinity of the pith was smallest, thus leading to rings intersecting the FRP plate in a more perpendicular manner. In addition, the denser older wood in the immediate vicinity of the pith contributes to higher bond strength. This is particularly evident in the large range of the results for the $120 \mathrm{~mm}$ and $180 \mathrm{~mm}$ bond length specimens.

\section{CONCLUSIONS}

A series of tests has been reported on the bond strength and behaviour of FRP-to-timber softwood joints. The results were found to be heavily influenced by the growth characteristics of the timber such as annual growth ring inclination to the bonded faces as well as the location of the pith. Knots were also found to affect the results. The existence of an effective bond length was confirmed and a lower bound bond strength was evident when the FRP was bonded to surfaces predominantly tangential (parallel) to the annual growth rings.

\section{ACKNOWLEDGEMENTS}

Financial support provided by GRF Incentive Award HKU 10208970 (09-10) is gratefully acknowledged.

\section{REFERENCES}

ASTM D 905-03 2003. Strength Properties of Adhesive Bonds in Shear by Compression Loading, American Society for Testing and Materials (ASTM), PA, USA.

Breyer, DE, Fridley, KJ, Cobeen, KE \& Pollock, DG 2007. Design of Wood Structures-ASD-LRFD, McGraw Hill, USA.

Claisse, PA, Davis, TJ \& Masse, B 2007. Fatigue testing of glass/epoxy joints in timber up to the endurance limit, Construction and Building Materials, 21: 139-149.

Crews, K \& Smith, ST 2006. Tests on FRP-strengthened timber joints, Proceedings, 3rd International Conference on FRP Composites in Civil Engineering, CICE 2006, Miami, FL, USA, 677-680.

Davalos, J.F., Qiao, PZ \& Trimble, BS 2000. Fiber-reinforced composite and wood bonded interfaces: Part 1. durability and shear strength, Journal of Composites Technology and Research, 22(4): 224-231.

Wan, J, Smith, ST \& Qiao, PZ. Bond strength and behaviour of FRP-to-softwood joints, in preparation. 